\title{
Conclusion: Reflecting on Studying Evidence Use from a Public Policy Perspective
}

\author{
Justin Parkhurst, Benjamin Hawkins, and Stefanie Ettelt
}

\section{Returning to the Question: What Does It Mean to Use Evidence in Policymaking?}

As Chap. 1 of this volume noted, the growth in interest in the use of evidence in policymaking has been remarkable in recent years. Nowhere has this been truer than in the area of health policy, given the close affiliation and historical associations with the evidence based medicine movement. There has been a proliferation of formal structures, bodies, processes and mechanisms within government and policy making designed to facilitate the use of evidence in decision making. Examples include new government agencies mandated with evidence synthesis, the establishment of health technology appraisal bodies, or the creation of standalone bodies at arm's length or independent from government, providing syntheses for

\footnotetext{
J. Parkhurst $(\bowtie)$

London School of Economics and Political Science, London, UK e-mail: j.parkhurst@lse.ac.uk

B. Hawkins • S. Ettelt London School of Hygiene and Tropical Medicine, London, UK e-mail: ben.hawkins@lshtm.ac.uk; stefanie.ettelt@lshtm.ac.uk

(C) The Author(s) 2018

J. Parkhurst et al. (eds.), Evidence Use in Health Policy Making, International Series on Public Policy, https://doi.org/10.1007/978-3-319-93467-9_11
} 
public policy information (such as the UK's 'what works centres'). Reflecting these developments, there has been a commensurate expansion in focus on the idea and practice of evidence use in policymaking amongst both scholars and practitioners. This is evident in the emergence, and increasing profile, of journals focussed specifically on evidence utilisation, such as Evidence os Policy or Implementation Science, and international events such as the Global Evidence Summit or the What Works Global Summit which are now held on a regular basis. The desire to engage with questions surrounding evidence use appears greater than ever.

Despite these important developments, the field of work looking at evidence use in policymaking appears to still be in its infancy, with scholars struggling to make sense of evidence use in real world settings. Policy scholars studying efforts made to achieve 'uptake' of research findings are often struck by the use of the language of 'evidence-based policy' in both academic and professional circles with little, if any, explicit definition of what counts as 'evidence' and what it means to have that evidence 'taken up' in policy decisions. At times, it seems easier to identify a policy community advocating for 'evidence-based policymaking', than to find clarity on what the term actually means. As discussed elsewhere (Parkhurst 2017), many champions of 'evidence based policy making' express explicit concern with problematic ways that evidence is used. This includes criticisms that policy makers ignore relevant evidence in decision making, or engage in 'cherry-picking' or manipulation of evidence for strategic ends. Yet the identification of unscientific practices and problems of bias in some political processes does not produce conceptual clarity about what real world practices of evidence use in policy making look like and, from a normative perspective, what they should look like.

Improving conceptual clarity requires a more nuanced understanding of the process of evidence production, the epistemological status of research outputs (i.e. the types of knowledge claims which are substantiated by a given study or piece of evidence) and the process of evidence use. Reflecting this, many policy scholars interested in questions of evidence use have shifted from a discourse of 'evidence based' to 'evidence informed' policymaking reflecting the realisation that evidence is one influence on policy amongst many (including ideological orientation of governments and societies and the political priorities and consent over the direction of policy by the populations affected by decisions). Moreover, the shift in language reflects the realisation that, while evidence can guide decisions, or inform us about the likely consequences of policy choices, it cannot 
guide what policy objectives governments ought to choose. This is particularly the case where governments face often mutually exclusive choices between competing policy agendas promoted by multiple policy advocates in the contexts of finite resources.

Chapter $\mathrm{l}$ also noted that there have been many attempts to identify the multiple ways research or evidence might influence policy, with works by those such as Carol Weiss $(1979,1982,1991)$, or Sandra Nutley, Huw Davies and colleagues (see Davies et al. 2000; Nutley et al. 2007, 2013) mapping out many of the most common ways that pieces of research or evidence appear to influence decisions. There is also no shortage of systematic reviews that have been conducted attempting to draw together empirical work on the subject, identifying barriers and facilitators to evidence use of one kind or another (c.f. Oliver et al. 2014; Mitton et al. 2007; Contandriopoulos et al. 2010; McCormack et al. 2013). However, there is still a gap in the literature relating to understanding the politics of evidence use, which warrants specific attention to be given to policy processes, the actors involved, the forms of contestation associated with policymaking, and the institutions that shape these processes and, by extension, evidence use.

A public policy perspective can integrate and move beyond initial typologies to understand the ways in which contextual factors shape evidence use in different policy environments. In particular, forms of political contestation around policy problems and their putative solutions, and institutional structures - including political systems in which policy responses are formulated and decisions are taken - shape the use of evidence in health policymaking. In the following sections, we reflect on how the case studies presented in the current volume provide insights into these three areas and into understanding the processes of evidence informed policy making more generally. We conclude with a broader discussion about the possible trajectories of future research agendas on evidence use in policymaking.

\section{InSTRUMENTAL Uses of EVIDENCE}

As has been identified previously (Smith 2013a; Russell et al. 2008; Cairney 2016), the public health community's language and thinking about evidence use often reflects Weiss' mostly instrumental meanings of research utilisation (i.e. her 'knowledge-driven' or 'problem-solving' models (Weiss 1979)). Yet politics and political systems tend to result in policy processes that rarely resemble this rational-linear, instrumental model (c.f. Weiss 1979, 1991; Russell et al. 2008; Hammersley 2013). 
Our case studies illustrate that there can be particular institutional arrangements in place which make instrumental uses of evidence more likely; arrangements that are typically created for exactly this purpose. The concept of evidence advisory systems, explored in Chap. 8 in particular, points to ways that formalised infrastructures might be deployed to ensure that both a supply of policy relevant evidence is available (e.g. research being undertaken, data collected, or bodies of evidence summarised), and that there are mechanisms through which decision makers can use policyrelevant evidence to inform decision making. We saw such systems have important effects in high income countries, with the Federal Joint Committee (GBA) in Germany and Public Health England being specifically mandated to review the evidence on policies within their remit.

Yet we also saw structural arrangements in lower and middle income settings playing important roles in driving instrumental uses of evidence. In Colombia (see Chap. 5), the implementation of organisations such as IETS (modelled on the example of the English National Institute for Health and Care Excellence (NICE), and tasked with providing health technology assessments similar to NICE) demonstrates the wider applicability of this model and the potential for trans-national knowledge transfer of evidence advisory systems, often via key individuals promoting a particular approach. In Ghana (Chap. 4), we further saw how the established national systems of data collection in healthcare fed into regular annual meetings that used such data to inform the evaluations of the health sector and plan for the future. Yet the Ghanaian case also illustrates that these systems do not remove political considerations or contestation from the processes of evidence use. Indeed, that chapter shows that they can routinise structures with decidedly political implications; with that chapter exploring how donor influence within this system could be seen to challenge local accountability processes. In a similar vein, contestation of evidence in case studies from Germany and England demonstrate that structures built to improve or rationalise evidence use cannot entirely prevent research evidence becoming embroiled in political debate and/or being used strategically to strengthen one side of a debate. Ultimately, we would argue that instrumental use relies on people actively prioritising this type of evidence use, sharing a belief that drawing on findings from research improves the quality of the outcome of decisions. In this sense, institutional structures to support the use of research in policy can work to embed this belief and reflect a willingness to enhance, and invest in, an instrumental role for research in supporting policy decisions. 


\section{Political Contestation and Strategic UsES OF EVIDENCE}

The existence of political contestation around the identification of policy problems and decisions on their proposed solutions, even within formalised advisory systems, underlines the fundamentally political nature of the policy process and the impossibility of stepping outside of politics even in the context of highly technical forms of decision making. Decisions about issues such as the prioritisation of different policy problems in the context of limited resources, or the way to address complex, multidimensional health issues which derive from multiple causal factors including those which are hard to define, isolate, and measure (e.g. the social determinants of health), will draw on multiple bodies of evidence - often in different forms and adhering to different epistemological norms. Unavoidably, the decision making process confronts different values, norms and political ideologies, in addition to whatever evidence has been chosen in support of the decision. An example of this is illustrated in the case study in Ethiopia (Chap. 3), whereby the multi-sectoral planning required to address nutrition in that country meant that multiple interests were relevant to a decision, and there were differing views on which evidence was therefore relevant or how to use it to inform decisions.

Yet we have also examined cases illustrating active disagreement between policy stakeholders about policy goals. This contestation could appear visibly, or it could be less explicit. In our aid-recipient nations, for instance, often the conflicts between the aims of international funding bodies and the agendas of national governments were not necessarily publicly debated. Interviews provided insights into how donor funding for particular research topics, or support for the construction of particular pieces of research (such as programmatic evaluations), could shape the evidence base to set policy priorities. Similarly, the political dynamics through which evidence of certain topics was brought to political decision processes was seen in some places as a mechanism for donor influence; as was the influence that could result when donors shaped the processes through which evidence and data are brought to bear on policy decisions (see discussion in Chap. 10; also Khan et al. 2017).

We found overt and explicit contestation more visible in our middle and higher income settings (although the extent to which conflict plays out 'behind the scene' was not investigated per se). In Colombia (Chap. 5 ), for instance, debates around national health system reform demonstrated 
the importance of different ideas about the relationship between the individual and the state and the role of the state and private enterprises in funding and providing healthcare in the incremental process of reforming the country's health system. Whilst evidence was called upon by all sides to support their positions, and was cited in draft legislation in support of proposals, it was unable to resolve conflicts between policy actors with deeply entrenched ideological positions.

In England (Chap. 7), we also saw how tobacco control debates around new nicotine delivery systems (e-cigarettes) have polarised the public health community and the strategic use of evidence to support the promotion of very different framing of the policy problem facing government and the regulatory approach it should take in addressing this. Evidence is cited by policy actors and researchers on both sides of the debate. For example, those who see the harm reduction potential of e-cigarettes point to studies showing reduced levels of toxicity in e-cigarette vapour versus tobacco smoke, whilst those taking a tobacco control perspective highlight the lack of epidemiological studies on their long term health effects. At this stage of the debate, with the need for significant additional research needed to remove uncertainty about the long-term health effects of e-cigarettes, recourse to evidence is unable to resolve conflicts between actors who view the issue in fundamentally different terms and from different professional perspectives.

The competitive nature of many policy environments can be seen to drive Weiss' (1979) idea of 'strategic' uses of evidence. In such cases, evidence is seen to be used as 'ammunition' to achieve pre-defined positions or policy goals - fundamentally to 'win' in the competitive process. Using evidence strategically may risk violating established principles of good scientific practice, however. It is also not compatible with notions of 'instrumental' use, although this distinction can be difficult to uphold and might well be part of the contestation. For example, in England, the public health community for many years collaborated effectively to influence government policy on tobacco control, strategically utilising scientific evidence to support their position. This was widely seen to be a legitimate use of evidence. Yet the tobacco industry also routinely engaged in strategic uses of evidence to support arguments in opposition to tobacco control measures, typically in ways judged to be biased by researchers and tobacco control advocates (c.f. Bero 2005; Lee et al. 2004; Ulucanlar et al. 2014).

Even rules-based health governance systems such as Germany's are open to strategic evidence use under conditions of contestation. The case 
study on minimum volume regulation (Chap. 6) demonstrated that while the Federal Joint Committee, the body mandated with setting minimum volumes, is required by law to appreciate the evidence in support of minimum volumes, its constituting member organisations were pitted against each other, with the German Hospital Association being strongly opposed to such regulation and marshalling its own evidence in support of its position. Evidence in this example was therefore used both instrumentally and strategically.

In our case studies, we found no indication that parliaments (explored in Chap. 9) were particularly prone to use evidence to inform decision (i.e. law) making. While this subject requires substantial additional research, this observation seems to suggest that in settings in which contestation is acted out openly and purposefully, the case for using evidence in an 'objective' or systematic way is harder to make. While there are structures in place in some countries to provide scientific advice to parliamentarians and committees, the emphasis of parliamentary process is on creating majorities and these majorities are typically formed within the context of party politics (although these can play out very differently in different parliamentary cultures as we have seen cross our case studies). There is a debate to be had about the extent to which parliaments should be better informed by evidence. It is certainly desirable for politicians to be literate in research use and for political parties to have their proposals questioned by recourse to evidence. Yet expecting parliament to operate in an 'evidence based' fashion seems to suggest an expectation that it is possible to reduce contestation in (i.e. depoliticise) political debate which is a contradiction in terms. In fact, this is more likely to happen in political systems that intentionally stifle or suppress contestation than in those with established democratic traditions.

\section{The Construction of Issues and Impact ON EVIDENCE USE}

While there may be both subtle and overt forms of contestation around evidence-informed policy debates, the case studies contained in this volume also point to a larger overarching theme important in shaping the use of evidence in health policy making. In particular, a number of cases explored the fundamental importance of issue construction and issue framing within local contexts in determining when and how evidence is used in the policy process. 
It might be expected that certain features of health problems make issues more or less conducive to particular types of evidence use. Such thinking is evident in the health policy literature, with the concept of 'issue characteristics' used by some to help explain global health policy agenda setting or the success of global health networks (Shiffman 2007; Shiffman et al. 2015). The importance of issue characteristics has also been proposed in other policy areas, for example, to understand what is considered rational policymaking in areas like global warming (Oshitani 2013), or to explain different bargaining strategies adopted within the EU by member states (McKibben 2010).

Within the health sector, scholars have argued that certain characteristics of policy issues might influence the ways in which evidence is used in decision making. For example, there is general recognition of cases where issues directly impact on private sector financial interests, which has led to strategic uses of evidence by corporate actors. Examples of this have been widely documented for the tobacco and alcohol industry for instance (Marmot 2004; Smith 2013b; Tong and Glantz 2007; McCambridge et al. 2014). We also see cases where policies are contested in terms of moral arguments about the appropriateness of certain behaviours, including sexual activity and drug use and the appropriate forms of treatment and the extent of resources which should be directed to tackling these conditions. A clear example of this surrounds arguments in favour of and against harm reduction approaches to injecting drug users (c.f Keane 2003; Rhodes et al. 2010; Buchanan et al. 2003), or debates about sexual health (c.f. Epstein 2006; Lyons 1999; Wald et al. 2001).

However, the concept of 'issue characteristics' deployed in much of the health policy literature is problematic, as it can assume an overly materialist and objectivist conception of the nature of social problems and underplays the extent to which policy problems are a result of inter-discursive processes of problem construction by policy actors. Moreover, it is possible that there will be multiple (sometime starkly conflicting) accounts of the 'same' policy issue within the same policy space. Similarly, we can find examples where seemingly technical issues, for which one might not expect contestation to arise around evidence use, could become problematized in unique ways, resulting in debates over evidence that might not be expected based on the nature of the policy decision (c.f. D'Souza and Parkhurst 2018).

Rather than health issues having inherent characteristics, it is, therefore, more appropriate to explore how different health issues are framed or constructed in particular ways in different settings, and to seek to understand 
the consequences of this for evidence use. In some of our lower-income fieldwork countries we asked interviewees about whether particular issues were highly contested, including asking about sexual health or HIV specifically. However, we did not find any respondents identifying any strong contestation over these in relation to their (current) work. In a similar vein, our interviews in Ghana identified little contestation or challenge around evidence use and policy formulation for tobacco control in that country - potentially explained by the fact that the country is not a tobacco producer and has relatively low smoking rates. This serves as a reminder that just because an issue may be deeply polarised and highly contested in one setting, it does not mean that the issue is inherently polarising. Nor does it meant that evidence around the issue will be necessarily used strategically, as has been seen with both HIV and tobacco control elsewhere (c.f. Parkhurst 2013; Parkhurst et al. 2015; Smith 2013b; and in Chap. 7 in this volume).

In Cambodia (Chap. 2), policy debates around HIV/AIDS was not found to be characterised by strong contestation along moral lines (according to our interviewees working primarily in national public health roles). Rather, it was presented as an example where evidence was used well in the country by respondents. In this case, 'good evidence use' was seen to be reflected in how international donor communities reviewed and relied on epidemiological studies to guide the choice of interventions for HIV/AIDS locally - a use of evidence that more reflects Weiss' instrumental modes.

Chapter 2 also illustrates just how fluid or dynamic the understanding of the concept of a 'good use' of evidence can be, and how this itself might be a construct of the specific context and policy needs. A second example mentioned by interviewees as exemplifying a good use of evidence was around a national programme providing financial incentives for health workers to encourage pregnant women to deliver in health facilities. When pressed further to explain why this was an exemplar, interviewees explained that there was 'evidence' of a problem of high maternal mortality, and a need to achieve progress towards the millennium development goal of reducing maternal mortality, and this intervention was clearly well targeted to achieve those goals. This conceptualisation of good evidence use for policy, however, is quite different from most conceptualisations in the global public health community. Instead, this judgement appears to have arisen from a broader idea that evidence can identify problems, and a proactive policy response to those problems (regardless of the efficacy of the intervention) would thus provide a good example of evidence use. 
Ultimately, our cases, and the broader literature on which they build, point to the ways in which evidence use in policymaking reflect the interaction between processes of issue framing and contestation. Thus, ideas about the appropriate or 'good' use of evidence use are not fixed or universal but vary between policy contexts and even between issues within the same context depending on the way in which a policy problem and their solutions are constructed and the institutional context in which policy decisions are taken.

\section{Adding Institutional Analysis}

From the policy perspective adopted in this volume, political institutions are of central importance to help understand the use of research evidence in health policymaking. Chapter 1 noted that there was a sizable gap in the literature of work exploring the institutional arrangements that work to shape which evidence is used, when, by whom, and to what ends. The chapters in this volume draw out a number of ways that institutions play key roles in shaping policy processes and by extension evidence use for health policymaking, providing a second key area of insight in addition to the nature of political contestation and issue construction.

One way institutions can influence evidence utilisation is by shaping which policy actors are involved in the policy process, or have access to those directly involved, and thus whose positions are considered. This was clearly illustrated in the analysis of Ghana (Chap. 4), where the formal processes of data analysis for policy review routinised the important roles that international donors had in the policy process. The comparative evaluation of evidence advisory systems in Chap. 8 similarly illustrated cases where some key stakeholders might be structured into policy-relevant positions due to institutional arrangements. In Germany's corporatist health governance system, non-state actors such as hospital or sickness fund associations, influence policy directly as they are legally mandated to be part of the top decision-making committee, while other actors have a minor or no role in decision making (e.g. patient organisations are consulted but do not have voting rights). Finally, the comparative analysis presented in Chap. 9 explored how formal authority over particular health decisions could lie with legislatures or judiciaries in countries, with important implications for how evidence would be considered and used as a result. Questions arise as to how these bodies are equipped when dealing 
with scientific evidence and whether there are limits to what can be achieved in terms of faithfulness to the scientific production of such evidence (Jasanoff and Nelkin 1981).

However, there can be less formal norms and practices that are institutionalised within key policymaking structures which could have implications for evidence use. March and Olsen's (2006) concept of institutional 'logics of appropriateness' can be seen to capture the ways that expectations about evidence, and understandings around how policy-relevant evidence can be embedded within different decision making bodies. Chapter 3 drew explicitly on this concept in Ethiopia to explore how the expectations and norms of evidence use could differ between government sectors, with potential implications for how evidence may or may not be used to inform multi-sectoral planning on nutrition. Similarly, the judicialisation of certain health policy decisions in Colombia (Chap. 5), particularly in relation to the provision of medicines and treatments led to different conceptualisations around what evidence is relevant to inform decisions than was the case in policy deliberations within the legislative-executive nexus (for a more detailed account, see Hawkins and Alvarez Rosete 2017). In Germany, courts grappled with the concept of 'hierarchies of evidence' demanding randomised controlled trials to provide the evidence in support of certain minimum volumes, irrespective of the fact that these studies do not exist and are not feasible to be conducted, especially not in the context of German hospital care. In addition, judicial decisions are typically based on the correct application of legally and constitutionally enshrined rights to specific individuals, but courts may be ill equipped to take account of the wider social and economic consequences of the decision, such as the implications of the ruling in question for resource allocation elsewhere in the system or the overall financial sustainability of the health system (although there are significant differences in legal practice in this respect between countries).

Institutions thus influence the use of evidence in policymaking for health in multiple ways. First, institutional arrangements can provide direction to both thinking and action involving evidence use. For example, the logics of appropriateness embedded within government institutions around evidence may make it more likely for civil servants to engage with research and evidence in some policy fields (health) than in others (justice) and in some countries (UK) than in others. Yet as discussed above, power and contestation remain highly relevant in the framing and 
problematisation of health issues, with important implications for evidence use. Second, institutions play a role in providing the venues in which such contestation and debate can take place. Institutional arrangements thus provide opportunities in terms of policy spaces where actors with access to these spaces can engage in issue construction and contestation processes. These processes may see stakeholders actively utilising pieces of evidence to problematize issues, but the resultant constructions will also establish frames of understanding that will have further implications for how different pieces of evidence are judged relevant to policy debates. For example, contestation of e-cigarette policy that in England largely played out within the scientific community and government public health bodies, in Germany led to legal challenge, so that the court system became the principal arena for contestation. This consequently limited the policy options for e-cigarette regulation in Germany, with little acknowledgement of the limited knowledge and research available at the time on the effects of e-cigarettes.

Third, while providing arenas for contestation and issue construction, institutional arrangements also serve to establish limits, with only certain actors having access to these spaces, or with the strength of norms and rules providing boundaries on how policy actors might shape and frame evidence to inform policy decisions. For example, Chap. 9 explored the roles of the judiciary and legislature and how these can play important roles in health policymaking and thus evidence use. As would be expected, those institutional arrangements regularly see contestation and debate, but they also shape and limit which types of actors and which types of arguments are made in relation to evidence use.

\section{Reframing Evidence Based Policy Making for the Public Health Sector}

Health sector actors regularly speak of the need to use evidence to achieve their goal of improving individual and population health. However, as has been discussed, what evidence use actually means can take a variety of forms and means different things in different contexts. Thus there is a need for more explicit reflection on what sorts of evidence use might best serve health sector goals, as well as recognition of the ways that public health actors' conceptualisations of evidence use may be insufficient given the realities of the policy process. 
The health sciences are in many ways deterministic, in as much as clinical medicine and epidemiology build on investigations of the natural world and physical bodies, and often seek to identify direct cause-effect relationships affecting human morbidity and mortality. Many key actors in the health sector have thus been trained in disciplines that look to control for context when considering interventions in order to be able to say 'what works' to reduce illness and improve health. From this perspective, it may seem logical or self-evident that strategies to increase evidence use will translate into more effective policies and interventions. Yet this fails to appreciate the existence of multiple relevant bodies of evidence and multiple ways in which that evidence may feed into complex policy decisions, in which health policy debates cannot be separated from the wider political context.

The fact that evidence use has many meanings is not a new insight, of course. However, this volume moves beyond a mapping of possible uses, to explore how different forms of evidence and evidence use arise and play out in relation to different issues and in different policy contexts. The case studies presented here illustrate how evidence use is shaped by various aspects of the policy, the institutional context in which policy decision are taken and the active agency of policy actors which will seek to frame perceptions of policy problems and their solutions in different ways, which impact in turn on the ways in which different bodies of evidence feed into the policy decisions.

A key message for health policy actors is to take on board the insights from policy analysis presented in this volume and appreciate the contextual nature of evidence informed policy making and the dependence of policy debates on issue and policy framing. This would move debates in this area beyond the identification of politics as a barrier to evidence use, to identify political contestation as a necessary and unavoidable characteristic of the policy process, which provides the context in which evidence use occurs. As we cannot move beyond, or step outside of politics, as some would hope, we must develop a more nuanced understanding of how evidence use occurs in the context of political contestation.

For those concerned with the use of evidence to achieve health improvements, this perspective can help to develop strategies which facilitate forms of evidence use that serve to identify the most efficient and effective solutions to accepted policy problems. It can also, however, serve as a means of facilitating the resolution of protracted policy conflicts. Indeed, a more widespread appreciation of the contested and political nature of policy making, and the existence of multiple framings of policy debates, amongst policy 
actors could potentially lead to more constructive forms of engagement in areas of vehement political contestation (such as the current debates about e-cigarettes in the UK); rather than seeing opposing sides of debates both selecting pieces of evidence on which to claim an 'evidence based' position (while simultaneously ignoring or dismissing their opponents claims over evidence). Understanding that different accounts of policy evidence result from different assessments of policy concerns and policy framings, may be one way to address the political polarisation over issues and increase the chances that competing actors seek effective policy solutions in good faith.

\section{Future Research Agendas}

The current volume identifies a number of potential directions for future research which build on the insights presented here. While the GRIPhealth programme, from which this volume emerged, attempted to sample a range of countries with differing levels of economic development and with differing forms of constitutional and institutional arrangements, the scope of analysis and comparison between cases was limited by the time and data available within an ambitious multi-country study. More focussed work should thus be undertaken to explore the different elements of evidence informed policy making that our chapters identify in greater depth, with significant scope for further comparative, politically informed studies of evidence use in low, middle, and high income settings.

For example, while Chap. 10 draws out lessons from aid-recipient settings, there are many further investigations that could be explored along these lines, including to investigate the governance implications of many new donor supported efforts to build systems of evidence use in lowincome settings. Even when not reliant on donor support, we are also seeing the development of new domestic administrative arrangements in relation to evidence use occurring in many low and middle income settings. These developments could provide a number of cases to explore how new arrangements governing evidence use are established and embedded and can provide a number of insights around institutionalisation of evidence advisory systems in these settings.

In higher income settings, there is also scope for further comparative work to gain insights into how different national political institutions (e.g. unitary vs federal systems) may interact with the establishment of evidence advisory systems at both national and sub-national levels. Indeed, even though two of our country case studies were federal systems (Germany 
and Ethiopia) the scope of work covered in this volume was unable to explore systems of evidence use below national levels to any significant degree. There will also be scope to reflect on different types of political systems and the degree to which they allow open contestation surrounding policy issues and whether or how this affects uses of evidence. Indeed, there is a need to go beyond the usual comparisons of countries that are seemingly similar in socio-economic terms and to think across low, middle and high income settings in a globalised world.

Approaches such as these could add much needed insights into how political and institutional factors work to shape the meaning of evidence utilisation in different settings, potentially offering lessons for those actors interested in improving evidence use according to one or another set of normative goals. At present, much public health literature remains focussed on the quality of evidence as judged by technical merits of research design, with broad calls for uptake of high quality evidence often made without consideration of the policy realities involved. As policy actors in the health field increasingly recognise that evidence utilisation is governed by systems working within political environments, they will need insights from work such as this to inform their efforts to improve the governance of evidence systems.

\section{REFERENCES}

Bero, Lisa A. 2005. Tobacco industry manipulation of research. Public Health Reports 120 (2): 200-208.

Buchanan, David, Susan Shaw, Amy Ford, and Merrill Singer. 2003. Empirical science meets moral panic: An analysis of the politics of needle exchange. Journal of Public Health Policy 24 (3/4): 427-444.

Cairney, Paul. 2016. The politics of evidence-based policymaking. London: Palgrave Pivot.

Contandriopoulos, Damien, Marc Lemire, Jean-Louis Denis, and ÉMile Tremblay. 2010. Knowledge exchange processes in organizations and policy arenas: A narrative systematic review of the literature. Milbank Quarterly 88 (4): 444-483. https://doi.org/10.1111/j.1468-0009.2010.00608.x.

D'Souza, Bianca, and Justin Parkhurst. 2018. When 'good evidence' is not enough: A case of global malaria policy development. Global Challenges. https://doi.org/10.1002/gch2.201700077

Davies, Huw T.O., Sandra M. Nutley, and Peter C. Smith. 2000. What works? Evidence based policy and practice in public service. Bristol: Polity Press. 
Epstein, Steven. 2006. The new attack on sexuality research: Morality and the politics of knowledge production. Sexuality Research and Social Policy 3 (1): 1-12. https://doi.org/10.1525/srsp.2006.3.1.01.

Hammersley, Martyn. 2013. The myth of research-based policy and practice. London: Sage.

Hawkins, Benjamin, and Arturo Alvarez Rosete. 2017. Judicialization and health policy in Colombia: The implications for evidence-informed policymaking. Policy Studies Journal. https://doi.org/10.1111/psj.12230

Jasanoff, Sheila, and Dorothy Nelkin. 1981. Science, technology, and the limits of judicial competence. Jurimetrics Journal 22: 266.

Keane, Helen. 2003. Critiques of harm reduction, morality and the promise of human rights. International Journal of Drug Policy 14 (3): 227-232. https:// doi.org/10.1016/s0955-3959(02)00151-2.

Khan, Mishal S., Ankita Meghani, Marco Liverani, Imara Roychowdhury, and Justin Parkhurst. 2017. Influences of external donors on national health policy processes: Experiences of local policy actors in Cambodia and Pakistan. Health Policy and Planning 33 (2): 215-233.

Lee, Kelley, Anna B. Gilmore, and Jeff Collin. 2004. Looking inside the tobacco industry: Revealing insights from the Guildford Depository. Addiction 99 (4): 394-397. https://doi.org/10.1111/j.1360-0443.2004.00718.x.

Lyons, Maryinez. 1999. Medicine and morality: A review of responses to sexually transmitted diseases in Uganda in the twentieth century. In Histories of sexually transmitted diseases and HIV/AIDS in Sub-Saharan Africa, ed. Philip W. Setel, Milton Lewis, and Maryinez Lyons. Westport: Greenwood Press.

March, James G., and Johan P. Olsen. 2006. The logic of appropriateness. In The Oxford handbook of public policy, ed. Michael Moran, Martin Rein, and Robert E. Goodin, 689-708. Oxford: Oxford University Press.

Marmot, Michael G. 2004. Evidence based policy or policy based evidence? Willingness to take action influences the view of the evidence - Look at alcohol. British Medical Journal 328 (17 April): 906-907.

McCambridge, Jim, Benjamin Hawkins, and Chris Holden. 2014. The challenge corporate lobbying poses to reducing society's alcohol problems: Insights from UK evidence on minimum unit pricing. Addiction (Abingdon, England) 109 (2): 199-205.

McCormack, Brendan, Joanne Rycroft-Malone, Kara DeCorby, Alison Hutchinson, Tracey Bucknall, Bridie Kent, Alyce Schultz, Erna SnelgroveClarke, Cheyl Stetler, Marita Titler, Lars Wallin, and Valerie Wilson. 2013. A realist review of interventions and strategies to promote evidence-informed healthcare: A focus on change agency. Implementation Science 8 (1): 107.

McKibben, Heather Elko. 2010. Issue characteristics, issue linkage, and states' choice of bargaining strategies in the European Union. Journal of European Public Policy 17 (5): 694-707. 
Mitton, Craig, Carol E. Adair, Emily McKenzie, Scott B. Patten, and Brenda W. Perry. 2007. Knowledge transfer and exchange: Review and synthesis of the literature. The Milbank Quarterly 85. https://doi.org/10.1111/ j.1468-0009.2007.00506.x.

Nutley, Sandra M., Isabel Walter, and Huw T.O. Davies. 2007. Using evidence: How research can inform public services. Bristol: The Policy Press.

Nutley, Sandra, Alison Powell, and Huw Davies. 2013. What counts as good evidence? London: Alliance for Useful Evidence.

Oliver, Kathryn, Simon Innvaer, Theo Lorenc, Jenny Woodman, and James Thomas. 2014. A systematic review of barriers to and facilitators of the use of evidence by policymakers. BMC Health Services Research 14 (1): 2 .

Oshitani, Shizuka. 2013. Global warming policy in Japan and Britain: Interactions between institutions and issue characteristics. Manchester: Manchester University Press.

Parkhurst, Justin. 2013. The subtle politics of AIDS: Values, bias, and persistent errors in HIV prevention. In Global HIV/AIDS politics, policy, and activism, ed. Raymond A. Smith, 113-139. Santa Barbara: Praeger.

Parkhurst, Justin. 2017. The politics of evidence: From evidence based policy to the good governance of evidence. Abingdon: Routledge.

Parkhurst, Justin, David Chilongozi, and Eleanor Hutchinson. 2015. Doubt, defiance, and identity: Understanding resistance to male circumcision for HIV prevention in Malawi. Social Science \& Medicine 135: 15-22.

Rhodes, Tim, Anya Sarang, Peter Vickerman, and Matthew Hickman. 2010. Policy resistance to harm reduction for drug users and potential effect of change. BMJ 341. https://doi.org/10.1136/bmj.c3439.

Russell, Jill, Trisha Greenhalgh, Emma Byrne, and Janet McDonnell. 2008. Recognizing rhetoric in health care policy analysis. Journal of Health Services Research \& Policy 13 (1): 40-46. https://doi.org/10.1258/ jhsrp.2007.006029.

Shiffman, Jeremy. 2007. Generating political priority for maternal mortality reduction in 5 developing countries. American Journal of Public Health 97 (5): 796-803.

Shiffman, Jeremy, Kathryn Quissell, Hans Peter Schmitz, David L. Pelletier, Stephanie L. Smith, David Berlan, Uwe Gneiting, David Van Slyke, Ines Mergel, and Mariela Rodriguez. 2015. A framework on the emergence and effectiveness of global health networks. Health Policy and Planning 31 (suppl_1): i3-il6.

Smith, Katherine. 2013a. Beyond evidence based policy in public health: The interplay of ideas. Basingstoks: Palgrave Macmillan.

Smith, Katherine. 2013b. Understanding the influence of evidence in public health policy: What can we learn from the 'tobacco wars'? Social Policy o Administration 47 (4): 382-398. 
Tong, Elisa K., and Stanton A. Glantz. 2007. Tobacco industry efforts undermining evidence linking secondhand smoke with cardiovascular disease. Circulation 116 (16): 1845-1854. https://doi.org/10.1161/circulationaha.107.715888. Ulucanlar, Selda, Gary J. Fooks, Jenny L. Hatchard, and Anna B. Gilmore. 2014. Representation and misrepresentation of scientific evidence in contemporary tobacco regulation: A review of tobacco industry submissions to the UK government consultation on standardised packaging. PLoS Medicine 11 (3): el001629. https://doi.org/10.1371/journal.pmed.1001629.

Wald, Kenneth D., James W. Button, and Barbara A. Rienzo. 2001. Morality politics vs. political economy: The case of school-based health centers. Social Science Quarterly 82 (2): 221-234.

Weiss, Carol H. 1979. The many meanings of research utilization. Public Administration Review 39 (5): 426-431.

- 1982. Policy research in the context of diffuse decision making. The Journal of Higher Education 53: 619-639.

1991. Policy research: Data, ideas, or arguments. In Social sciences and modern states: National experiences and theoretical crossroads, ed. Peter Wagner, Carol Hirschon Weiss, Björn Wittrock, and Hellmut Wollmann, 307-332. Cambridge: Cambridge University Press.

Open Access This chapter is licensed under the terms of the Creative Commons Attribution 4.0 International License (http://creativecommons.org/licenses/ by $/ 4.0 /$ ), which permits use, sharing, adaptation, distribution and reproduction in any medium or format, as long as you give appropriate credit to the original author(s) and the source, provide a link to the Creative Commons license and indicate if changes were made.

The images or other third party material in this chapter are included in the chapter's Creative Commons license, unless indicated otherwise in a credit line to the material. If material is not included in the chapter's Creative Commons license and your intended use is not permitted by statutory regulation or exceeds the permitted use, you will need to obtain permission directly from the copyright holder.

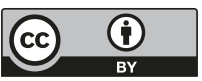

